\title{
Participation and Activity Rates: Monitoring Exposure Potential for Native Americans and Others in the United States ${ }^{*}$
}

\section{Joanna Burger}

Division of Life Sciences, Rutgers University, Piscataway, USA

Email: burger@biology.rutgers.edu

Received May $17^{\text {th }}, 2011$; revised July $9^{\text {th }}, 2011$; accepted August $13^{\text {th }}, 2011$.

\begin{abstract}
Managers and regulators are concerned about potential human health effects from exposure on lands contaminated by chemicals and radionuclides. Determining target cleanup levels is partly dependent upon future land use, and potential exposure from human use. This paper provides data from surveys of activity patterns of people attending festivals in four states, located in the vicinity of Department of Energy facilities. There were significant differences in both participation rates, and activity rates as a function of both location and ethnicity that can be used by managers to track exposure, land use, and preferred activities on natural lands. In general, 1) a higher percent of Native Americans engaged in consumptive activities than others, 2) a higher percent of Caucasians engaged in some non-consumptive activities than Native Americans, 3) a higher percentage of Native Americans engaged in activities on sacred grounds, 4) activity rates were generally higher for Native Americans for consumptive activities and religious/cultural than for Caucasians, 5) fishing rates were higher than other consumptive activities, and camping/hiking were higher than other non-consumptive activities, and 6) hunting rates were higher in subjects from Idaho than elsewhere. Baseline human use is critical for monitoring potential exposure, and provides the basis for monitoring, risk assessment and future land use, and these data can be used by managers for assessment and management. Tracking changes over time will reflect changing recreational, subsistence, and cultural/religious trends that relate to land use, public perceptions, and exposure.
\end{abstract}

Keywords: Monitoring, Baseline, Exposure, Ethnicity, Native Americans, Caucasians, Department of Energy

\section{Introduction}

The USA and World are moving toward managing land for ecological, economic, and societal values. While considerable attention has been devoted to assessment and monitoring of species, populations, and ecosystems, relatively little has been devoted to assessing human use of relatively intact ecosystems, including participation rates, activity patterns, and ethnic differences in resource use. Both managing and restoring degraded ecosystems depends not only on understanding the structure and function of ecosystems, but human use and values.

Restoring degraded ecosystems and natural resources is an important activity for federal and state governments, Tribal Nations, scientists, managers, the private sector, and the public. An important component of management is characterizing the current state of the ecosystem, and its degradation, including determining the appropriate and desired outcome, as well as human use [1-3]. Assessing contamination, evaluating ecosystem damage, and considerations of future land use require an understanding not only of hazard identification, contamination assessment (temporal and spatial patterns), and ecosystem evaluation (injuries at the individual, population, community and ecosystem level), but an assessment of human use.

Burger et al. [4] suggest that while most economists and other Western scientists value the goods and services that ecosystems provide, subsistence and Native Americans have a broader, more holistic view of the interrelationship of natural and cultural resources. A healthy ecosystem is one that supports its natural plants and animals, as well as sustaining the biophysical, cultural, and spiritual health of native peoples [5-11]. They suggested that 1) subsistence and tribal peoples view natural resources holistically and combine traditional goods and services 
together rather than considering them separately, 2) many individual, religious and cultural activities encompass a holistic view of nature (intact, not-degraded, and not polluted), and 3) resources considered to be cultural by Western scientists have a natural resource base as an integral part of cultural use by Native Americans (e.g. a sacred ground includes man made and the physical environment [4]). Thus, assessing human use of natural ecosystems (or restored ecosystems) should also include understanding whether people, particularly Native Americans, use the lands for religious and cultural purposes.

There are nearly 600 recognized American Indian Tribes in the United States, and many are located near contaminated lands that were once their traditional tribal lands. Understanding how Native Americans and others use the land, what percentage engage in different types of activities, and the frequency of engagement is critical to assessing and monitoring potential exposure. The assessment of resource use by people is particularly critical where multiple land uses are concerned [12], or where different ethnic groups may use the land in different ways.

This paper examines human use and activity patterns of subjects interviewed at four venues in Idaho, Tennessee, New York and New Jersey, focusing on location and ethnic differences (particularly Native Americans and Caucasians). All four venues were in the vicinity of Department of Energy (DOE) sites, where environmental restoration and management are aimed at reducing risk to humans and the environment [13-15], and where there are important ecological resources[4,16]. Three types of activities are explored: consumptive, non-consumptive, and religious/sacred. Understanding the activity patterns is also important because it fits within the DOE's environmental justice program for fair treatment and meaningful involvement for all people, and to ensure that fair treatment such that no group bears a disproportionate share of negative environmental consequences [17].

\section{Methods and Protocol}

Our overall research design was to interview people attending four events (or series of event) near major DOE sites. These included 1) the Julyamsh Pow Wow (=Indian festival) at Post Falls, Idaho (in region with Hanford Site), 2) the Shoshone Bannock festival at Ft. Hall (near the Idaho National Laboratory), 3) Pow Wow on the Mountain in Cookeville (near Oak Ridge Reservation in Tennessee), and 4) Gateway to Nations in Brooklyn New York and the Sussex County Pow Wow in New Jersey (near Brookhaven National Laboratory, combined because of their proximity) (Figure 1).

We selected these events because we expected there to be both Native Americans and Caucasians. All were in the region with well-known contaminated DOE sites, and we expected there to be an adequate sample of both Native Americans and others. The events attracted a general public and not just people interested in natural resources, and the events went for several days, providing the opportunity to interview a sufficient sample of subjects. Further, these were festivals in which hunting, fishing, camping or other outdoor activities were not featured, and a cross-section of people might be expected to attend (albeit people interested in Native American culture).

Our overall protocol was to use structured interviews, employing a questionnaire to assess resource uses, perceptions about the features of the environment that were important to them, resource activity rates (by consumptive, non-consumptive uses, and religious/sacred), perceptions about Natural Resource Damage Assessment and resource restoration, and perceptions of who should restore natural resources. The data for this paper only includes participation in activities and activity rates.

All questionnaires were administered by trained personnel who had conducted these interviews in the past. The interviews required between $20 \mathrm{~min}$ and $40 \mathrm{~min}$, depending upon how many activities subjects engaged in, and how many questions subjects asked about the survey or natural resources. People were interviewed while they waited in lines or for activities to begin, and few people declined to be interviewed. Interviewers first introduced themselves as from Rutgers University, and explained the overall purpose of the survey. We randomly selected a person for the interview, and after completing the interview, moved at least three meters in a transect across the fair grounds, to select the next prospective interviewee. In some cases we moved along a waiting line in this manner, and in other cases we moved through the crowd in this manner. Subjects were not selected completely randomly, but there is no reason to assume a bias in our selection process. Rather, the data are used to examine locational and ethnic differences useful for managers to consider.

The questionnaire was divided into sections that included demographics, rating of the importance of environmental features by consumptive and non-consumptive activities, frequency of various activities (and relative importance of each), and questions about Natural Resource Damage Assessment and restoration. Demographic information included age, gender, education, family income (asked at the end of the interview), self-identified ethnicity, self-identified tribal affiliation, and whether they had ever worked for the Department of Energy.

We asked whether they hunted, fished, crabbed, gathered herbs or berries, or engaged in other consumptive activities, and then asked them to provide information on their activity rates. We asked them to rate the importance 
of different activities on a Likert scale of 1 [unimportant] to 5 [very important]). We also asked them to rate (on a scale of $1-8$ ) eight different activities, where only one activity could be rated 1 , and only one could be rated 2 , and so on. We also asked about non-consumptive activities, such as hiking, bird watching, biking, camping, picnicking and other, as well as religious/sacred activities.

We used Kruskal-Wallis $\chi^{2}$ tests to distinguish differences among Caucasians and Native Americans within and among sites [18]. We accepted $\mathrm{P}<0.05$ as significant, and give means and standard errors in the text and figures. As with all survey research, the results reflect the populations interviewed and are not necessarily representative of either specific groups of Caucasians or Native Americans.

\section{Results}

\subsection{Demographics}

There were demographic differences in the subjects among the four study sties (Table 1). A higher level of education was obtained in subjects interviewed in Post Falls and New Jersey/New York than the other locations.

Table 1. Demographics of study population in Cookeville, Tennessee, Post Falls and Fort Hall, Idaho, Sussex County, New Jersey, and Brooklyn, New York (2009). Given are means \pm standard error and range for age and income.

\begin{tabular}{|c|c|c|c|c|c|c|c|c|c|}
\hline $\mathrm{n}^{\mathrm{a}}$ & $\begin{array}{l}\text { Education } \\
\left.\text { (years }^{\text {b }}\right)\end{array}$ & $\begin{array}{c}\text { Less than } \\
\text { high school }\end{array}$ & $\begin{array}{l}\text { High } \\
\text { school }\end{array}$ & $\begin{array}{l}\text { Some } \\
\text { college }\end{array}$ & $\begin{array}{l}\text { College } \\
\text { graduate }\end{array}$ & $\begin{array}{c}\text { Graduate } \\
\text { level }\end{array}$ & $\begin{array}{c}\text { Income } \\
\text { (thousands of } \\
\text { dollars) }\end{array}$ & Age & $\begin{array}{c}\text { Gender } \\
(\% \text { Women })\end{array}$ \\
\hline
\end{tabular}

Post Falls, Idaho

\begin{tabular}{|c|c|c|c|c|c|c|c|c|c|c|}
\hline Overall & 401 & $14.2 \pm 0.1$ & $9 \%$ & $28 \%$ & $22 \%$ & $35 \%$ & $6 \%$ & $48.5 \pm 2.6,0-500$ & $\begin{array}{c}46.5 \pm 0.8 \\
13-87\end{array}$ & $55 \%$ \\
\hline Native American & 209 & $13.6 \pm 0.2$ & $15 \%$ & $33 \%$ & $20 \%$ & $28 \%$ & $3 \%$ & $43.3 \pm 4.1,0-500$ & $\begin{array}{c}41.8 \pm 1.1 \\
16-87\end{array}$ & $50 \%$ \\
\hline Caucasian & 177 & $14.8 \pm 0.2$ & $2 \%$ & $22 \%$ & $24 \%$ & $45 \%$ & $8 \%$ & $53.6 \pm 3.3,6-300$ & $\begin{array}{c}52.5 \pm 1.1 \\
18-86\end{array}$ & $58 \%$ \\
\hline
\end{tabular}

Fort Hall, Idaho

$\begin{array}{ccccccc}\text { Overall } & 387 & 13.8 \pm 0.1 & 13 \% & 33 \% & 13 \% & 35 \% \\ \text { Native American } & 268 & 13.6 \pm 0.2 & 16 \% & 35 \% & 13 \% & 32 \% \\ \text { Caucasian } & 108 & 14.2 \pm 0.2 & 6 \% & 31 \% & 14 \% & 43 \%\end{array}$

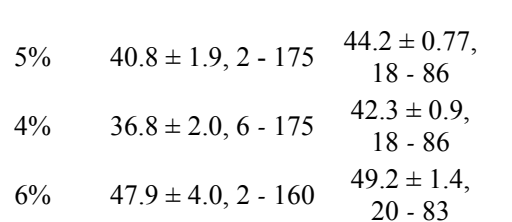

$50 \%$

$53 \%$

$43 \%$

Cookeville, Tennessee

$\begin{array}{crr}\text { Overall } & 233 & 13.4 \pm 0.1 \\ \text { Native American } & 92 & 13.3 \pm 0.2 \\ \text { Caucasian } & 128 & 13.4 \pm 0.2 \\ & & \\ \text { sex } & & \\ \text { New Jersey \& Brooklyn New York }\end{array}$

$\begin{array}{ccc}\text { Overall } & 240 & 14.8 \pm 0.2 \\ \text { Native American } & 63 & 14.5 \pm 0.4 \\ \text { Caucasian } & 98 & 15.0 \pm 0.2 \\ \text { Comparison among 4 locations } & \\ \text { Overall } \mathrm{X}^{2} \text { (p) } & 1261 & \begin{array}{c}45.7 \\ (<0.0001)\end{array} \\ \text { Native American } \mathrm{X}^{2} & 632 & \begin{array}{c}7.8(0.05) \\ (\mathrm{p})\end{array} \\ \begin{array}{c}\text { Caucasian } \mathrm{X}^{2} \text { (p) } \\ \text { N }\end{array} & 511 & \begin{array}{c}33.6 \\ (<0.0001)\end{array}\end{array}$

$\begin{array}{llll}43 \% & 19 \% & 23 \% & 3 \% \\ 44 \% & 23 \% & 23 \% & 2 \% \\ 43 \% & 16 \% & 23 \% & 4 \%\end{array}$

$39.2 \pm 2.3,1-190+47$.

$$
\begin{array}{cc}
39.2 \pm 2.3,1-190 & 47.3 \pm 0.9 \\
& 14-81 \\
35.4 \pm 3.7,1-145 \quad & 48.5 \pm 1.5 \\
& 14-79
\end{array}
$$$$
\begin{array}{cc} 
& 47.0 \pm \\
42.7 \pm 3.3,1.5-190 & 12,18-8
\end{array}
$$

$58 \%$

$40 \%$

$56 \%$

$1.2,18-81$

$56 \%$

Sussex, New Jersey \& Brooklyn New York

$$
\begin{array}{ccc}
\begin{array}{ccc}
\text { Overall } & 240 & 14.8 \pm 0.2 \\
\text { Native American } & 63 & 14.5 \pm 0.4 \\
\text { Caucasian } & 98 & 15.0 \pm 0.2 \\
\text { Comparison among 4 locations } & \\
\text { Overall } \mathrm{X}^{2}(\mathrm{p}) & 1261 & \begin{array}{c}
45.7 \\
(<0.0001)
\end{array}
\end{array}
\end{array}
$$$$
8 \% \quad 28 \% \quad 11 \% \quad 42 \%
$$$$
14 \% \quad 24 \% \quad 19 \% \quad 37 \%
$$$$
11 \% \quad 65.3 \pm 2.6,10-160
$$$$
47.5 \pm 0.9
$$$$
16-84
$$$$
6 \% \quad 57.4 \pm 4.7,20-120 \quad \begin{gathered}
48.9 \pm 1.9, \\
22-84
\end{gathered}
$$$$
17 \%
$$$$
69.1 \pm 4.6,10-160
$$$$
49.7 \pm 1.4
$$

$50 \%$

$41 \%$

$57 \%$

$$
\begin{array}{ccc}
87.7(<0.0001) & 10.7(0.01) & 5.0(\mathrm{NS}) \\
23.5(<0.0001) & \begin{array}{c}
22.0 \\
(<0.0001)
\end{array} & 4.9(\mathrm{NS}) \\
31.1(<0.0001) & 12.3(0.006) & 7.7(0.05)
\end{array}
$$

Comparison of all Native American to Caucasian

$$
\begin{array}{cc} 
& 23.8 \\
\mathrm{X}^{2}(\mathrm{p}) & (<0.0001)
\end{array}
$$

$36.4(<0.0001)$

43.6
$(<0.0001)$

$1.2(\mathrm{NS})$ 
Although the educational levels varied by site for both Native Americans and Caucasians, the differences were greater for Caucasians than for Native Americans. Income tracked education in that the places with the lower levels of education (Ft. Hall and Cookeville) had significant lower mean incomes than those from the other places: incomes from subjects interviewed in New Jersey/New York were significantly higher than those of subjects from other sites. Although there were significant differences in age among the locations, the differences were small (mean age varied from 44.2 to 47.5 years (Table 1). Overall, for all subjects combined $(\mathrm{N}=1261)$, Native Americans had less education and had lower incomes than did Caucasians.

\subsection{Participation Rates}

One measure of potential use of an area, and thus potential exposure if sites are contaminated, is the percent of people that engage in different activities. Overall, between $52 \%$ and $76 \%$ of the subjects interviewed, depending upon the location, engaged in consumptive activities, $84 \%$ to $89 \%$ engaged in non-consumptive activities, and $64 \%$ to $76 \%$ of the subjects engaged in religious/sacred activities (Table 2). Participation in fishing was higher than for other consumptive activities. In several locations there was a higher participation rate in gathering herbs and berries than in hunting. There were significant locational differences for all activities, except crabbing (few people engaged regardless of location) and some religious activities.

For all 4 sites, a higher percentage of Native Americans engaged in consumptive activities (fish, hunt, gather) than did Caucasians (Table 2, Figure 2). A higher percentage of Caucasians engaged in specific non-consumptive activities than did Native Americans (except for camping). For all sites, a higher percentage of Native Americans engaged in religious/sacred activities than did Caucasians, and these differences were also consistent within sites (Table 2).

\subsection{Activity Rates}

A second measure of land use and potential exposure is activity rates (mean number of days/month) for different activities. Activity rates were computed only for those people who engaged in each activity, since to do otherwise is biased toward lower activity rates (because of the large number of 0 days). Activity rates for hunting/fishing/crabbing and for collecting herbs and berries, the two consumptive activities we asked about, were lower for all four sites, than were non-consumptive activity rates (bird- watch, hike, pray, Table 3).

Several conclusions can be drawn from Table 3 and Figure 3: 1) there were significant location differences for 6 of the 8 activities, 2) there were location differences when only Native Americans are considered for all but communing with nature, 3 ) there were location differences for only 2 of 8 activities for Caucasians, 4) when all subjects were lumped, there were differences between Native Americans and Caucasians for only 5 of 8 activities, and 5) subjects had the highest rates for commune with nature and pray or meditate for all locations. The greatest location difference for Native Americans was for hiking/biking/walking; rates were highest for New Jersey/New York. The greatest location difference for Caucasians was for fish/hunt/crab; rates were highest for Ft. Hall.

\subsection{Most Important Activities}

In the previous two sections, subjects provided information on whether they engaged in particular activities, and

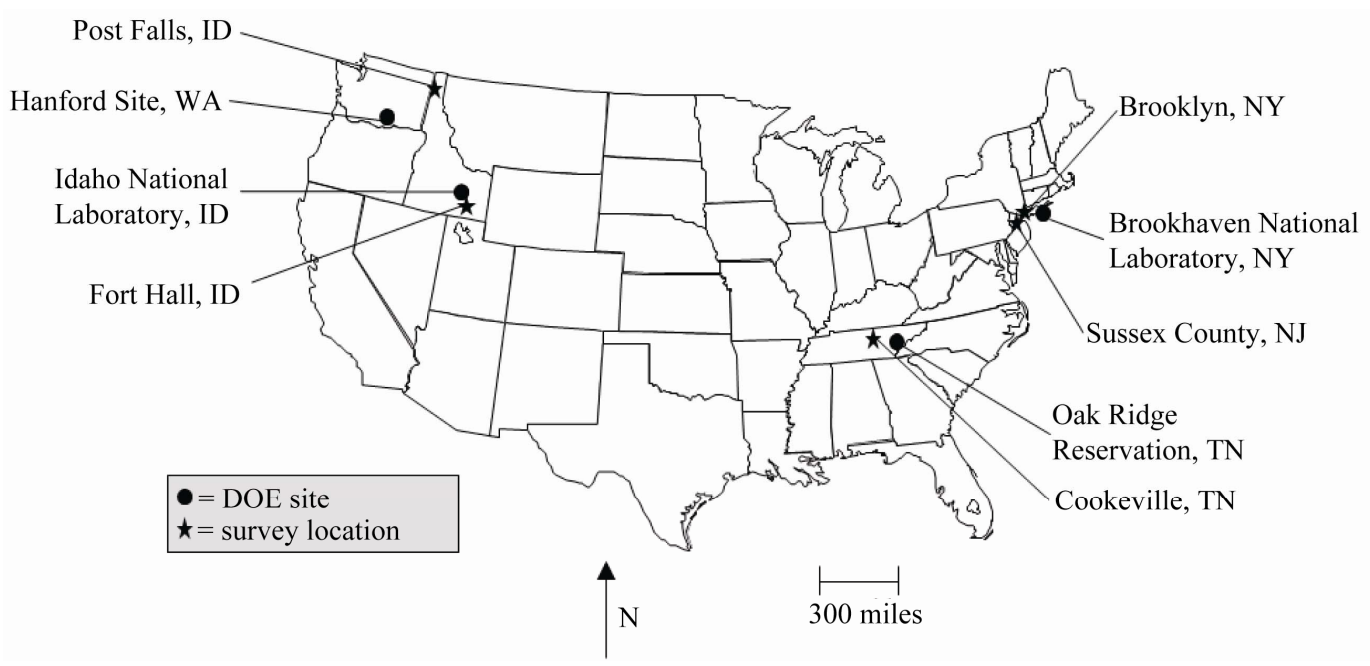

Figure 1. Map showing the sampling four survey locations and relative Department of Energy sites. 
Table 2. Percent of respondents that use natural areas for consumptive, non-consumptive, and religious/sacred purposes.

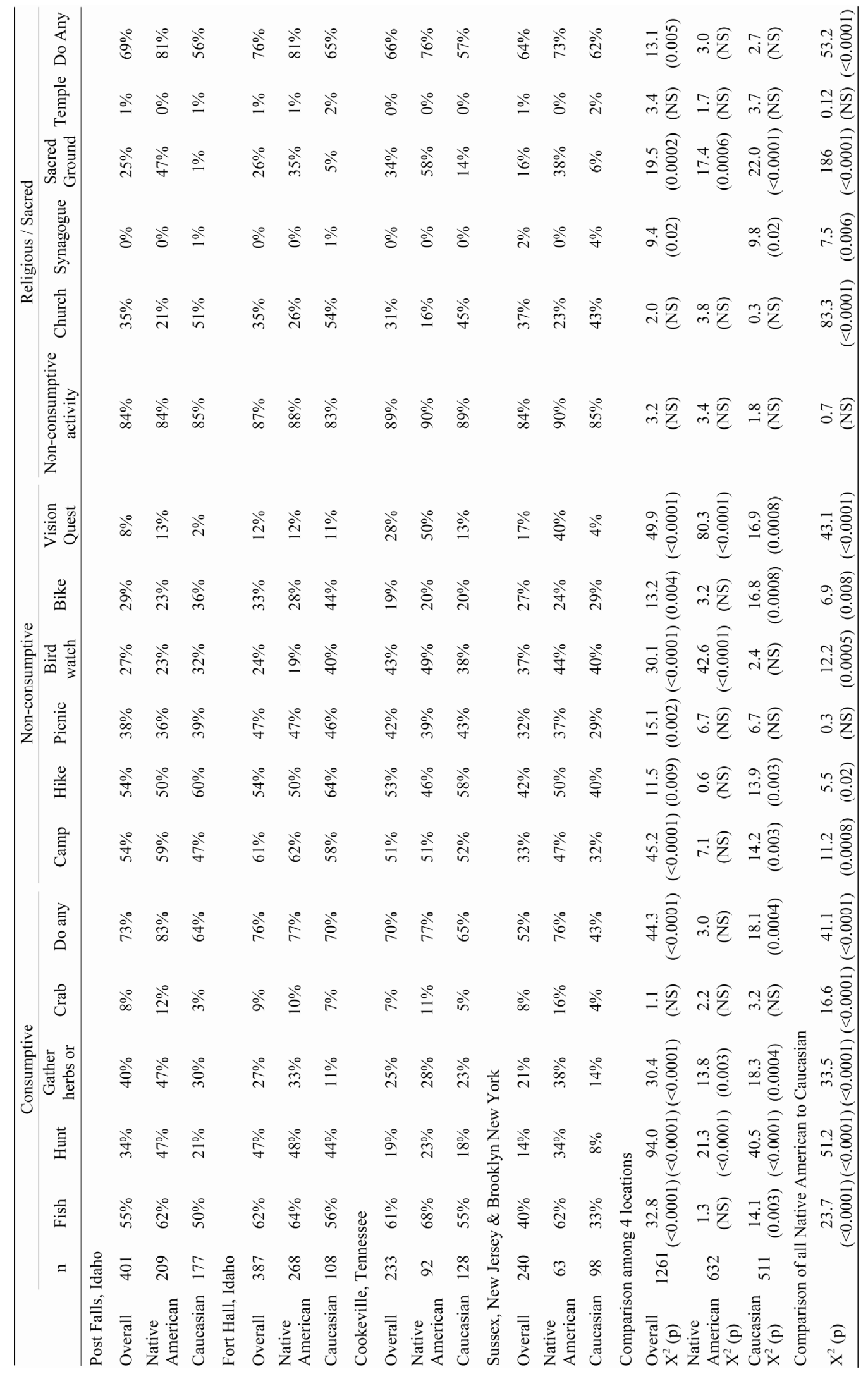


1014 Participation and Activity Rates: Monitoring Exposure Potential for Native Americans and Others in the United States

Table 3. Mean number of times per month respondents participate in activities (for those who do the activity). Given are means \pm standard error and Kruskal-Wallis $\mathrm{X}^{2}(\mathbf{p})$.

\begin{tabular}{|c|c|c|c|c|c|c|c|c|c|c|c|c|c|c|c|c|}
\hline & $\mathrm{n}$ & $\begin{array}{c}\text { Fish, Crab, } \\
\text { or hunt per } \\
\text { Month }\end{array}$ & $\mathrm{n}$ & $\begin{array}{c}\text { Collect } \\
\text { Herbs and } \\
\text { berries per } \\
\text { month }\end{array}$ & $\mathrm{n}$ & $\begin{array}{l}\text { Bird watch } \\
\text { per month }\end{array}$ & $\mathrm{n}$ & $\begin{array}{l}\text { Commune } \\
\text { with Nature } \\
\text { per month }\end{array}$ & $\mathrm{n}$ & $\begin{array}{c}\text { Pray or } \\
\text { meditate } \\
\text { per month }\end{array}$ & $\mathrm{n}$ & $\begin{array}{l}\text { Picnic or } \\
\text { feast per } \\
\text { month }\end{array}$ & $\mathrm{n}$ & $\begin{array}{l}\text { Hike, } \\
\text { Walk, or } \\
\text { Bike per } \\
\text { month }\end{array}$ & $\mathrm{n}$ & $\begin{array}{c}\text { Vision } \\
\text { quest or } \\
\text { other } \\
\text { ceremony } \\
\text { per month }\end{array}$ \\
\hline \multicolumn{17}{|c|}{ Post Falls, Idaho } \\
\hline Overall & 204 & $4.6 \pm 0.4$ & 170 & $3.7 \pm 0.4$ & 165 & $15.0 \pm 1.0$ & 314 & $18.6 \pm 0.7$ & 242 & $20.4 \pm 0.8$ & 261 & $5.4 \pm 0.4$ & 312 & $12.2 \pm 0.6$ & 90 & $3.6 \pm 0.7$ \\
\hline $\begin{array}{c}\text { Native } \\
\text { American }\end{array}$ & 118 & $5.5 \pm 0.6$ & 109 & $4.0 \pm 0.5$ & 84 & $14.7 \pm 1.4$ & 168 & $20.8 \pm 0.9$ & 149 & $22.0 \pm 0.9$ & 140 & $5.2 \pm 0.5$ & 158 & $13.3 \pm 0.9$ & 77 & $3.5 \pm 0.7$ \\
\hline Caucasian & 83 & $3.3 \pm 0.3$ & 59 & $3.3 \pm 0.7$ & 79 & $15.4 \pm 1.4$ & 137 & $16.1 \pm 1.1$ & 89 & $18.2 \pm 1.4$ & 111 & $5.6 \pm 0.7$ & 145 & $10.9 \pm 0.9$ & 12 & $5.0 \pm 2.4$ \\
\hline
\end{tabular}

Fort Hall, Idaho

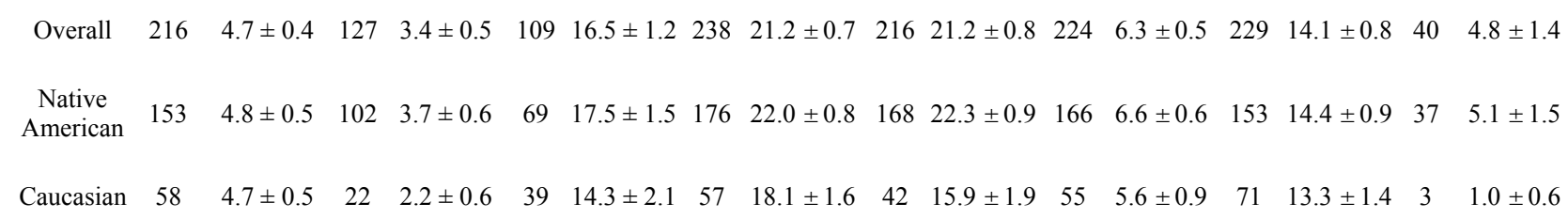

Cookeville, Tennessee

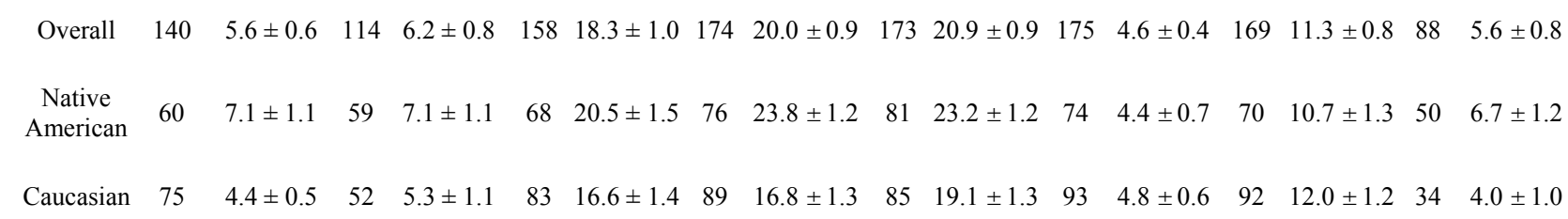

Sussex, New Jersey \& Brooklyn New York

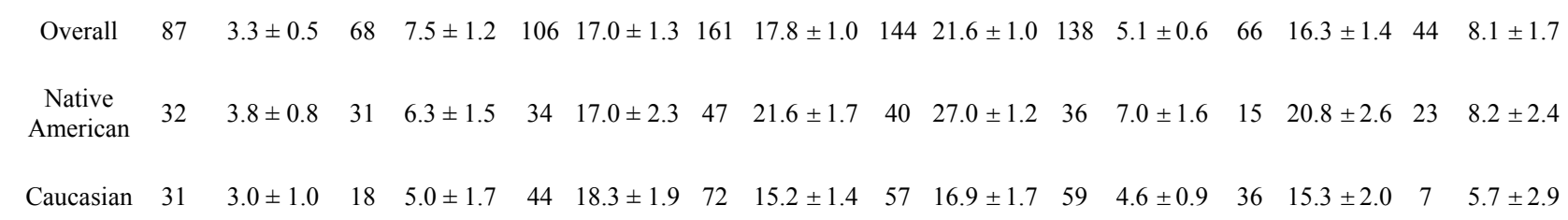

Comparison among 4 locations

\begin{tabular}{|c|c|c|c|c|c|c|c|c|}
\hline $\begin{array}{l}\text { Overall } X^{2} \\
\text { (p) }\end{array}$ & $12.8(0.005)$ & $\begin{array}{c}15.7 \\
(0.001)\end{array}$ & $5.5(\mathrm{NS})$ & $\begin{array}{c}11.5 \\
(0.009)\end{array}$ & 1.7 (NS) & $\begin{array}{c}17.2 \\
(0.0007)\end{array}$ & $\begin{array}{c}16.2 \\
(0.001)\end{array}$ & $10.0(0.02)$ \\
\hline $\begin{array}{c}\text { Native } \\
\text { American } \\
\mathrm{X}^{2}(\mathrm{p})\end{array}$ & $10.3(0.02)$ & $10.7(0.01)$ & $9.4(0.02)$ & $5.0(\mathrm{NS})$ & $8.6(0.04)$ & $8.1(0.04)$ & $\begin{array}{c}14.1 \\
(0.003)\end{array}$ & $9.6(0.02)$ \\
\hline $\begin{array}{c}\text { Caucasian } \\
\mathrm{X}^{2}(\mathrm{p})\end{array}$ & $12.5(0.006)$ & $8.1(0.04)$ & 1.5 (NS) & 3.1 (NS) & 2.7 (NS) & $7.0(\mathrm{NS})$ & 6.7 (NS) & $2.0(\mathrm{NS})$ \\
\hline
\end{tabular}

Comparison of all Native American to Caucasian

$$
\begin{array}{lllllll}
\mathrm{X}^{2}(\mathrm{p}) & 3.5(\mathrm{NS}) & 6.4(0.01) & 0.7(\mathrm{NS}) & 37.2(<0.0001) & 26.1(<0.0001) & 4.1(0.04)
\end{array}
$$

${ }^{\text {a }}$ This includes camping, horseback riding, sweat lodge, sports, shooting, rodeo, butterfly watching, animal watching, gardening, swimming and boating. 

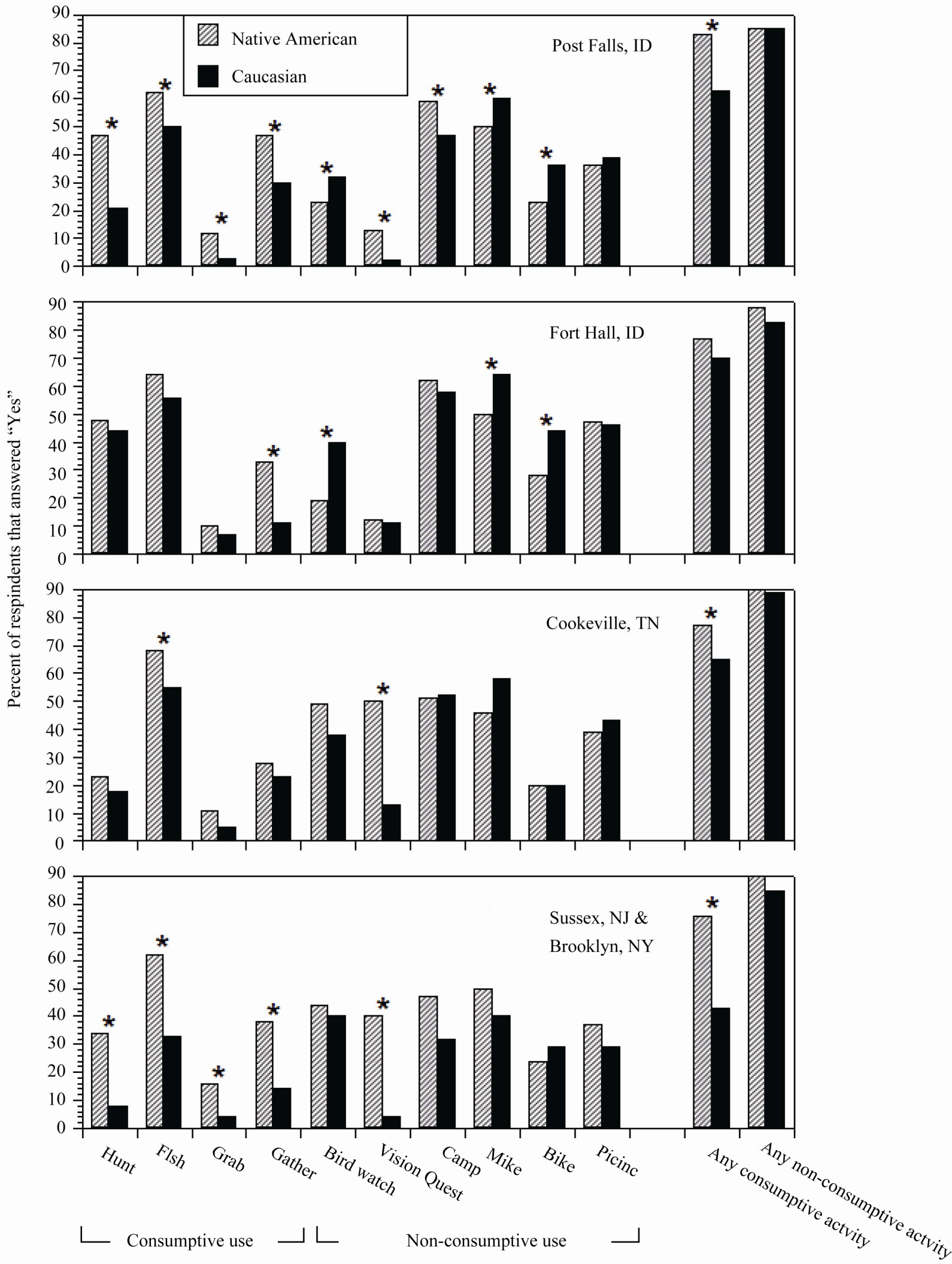

Figure 2. Percentage of Native Americans and Caucasian who said they engaged in specific consumptive and non-consumptive activities at all locations. Star indicates a significant difference. 
1016 Participation and Activity Rates: Monitoring Exposure Potential for Native Americans and Others in the United States
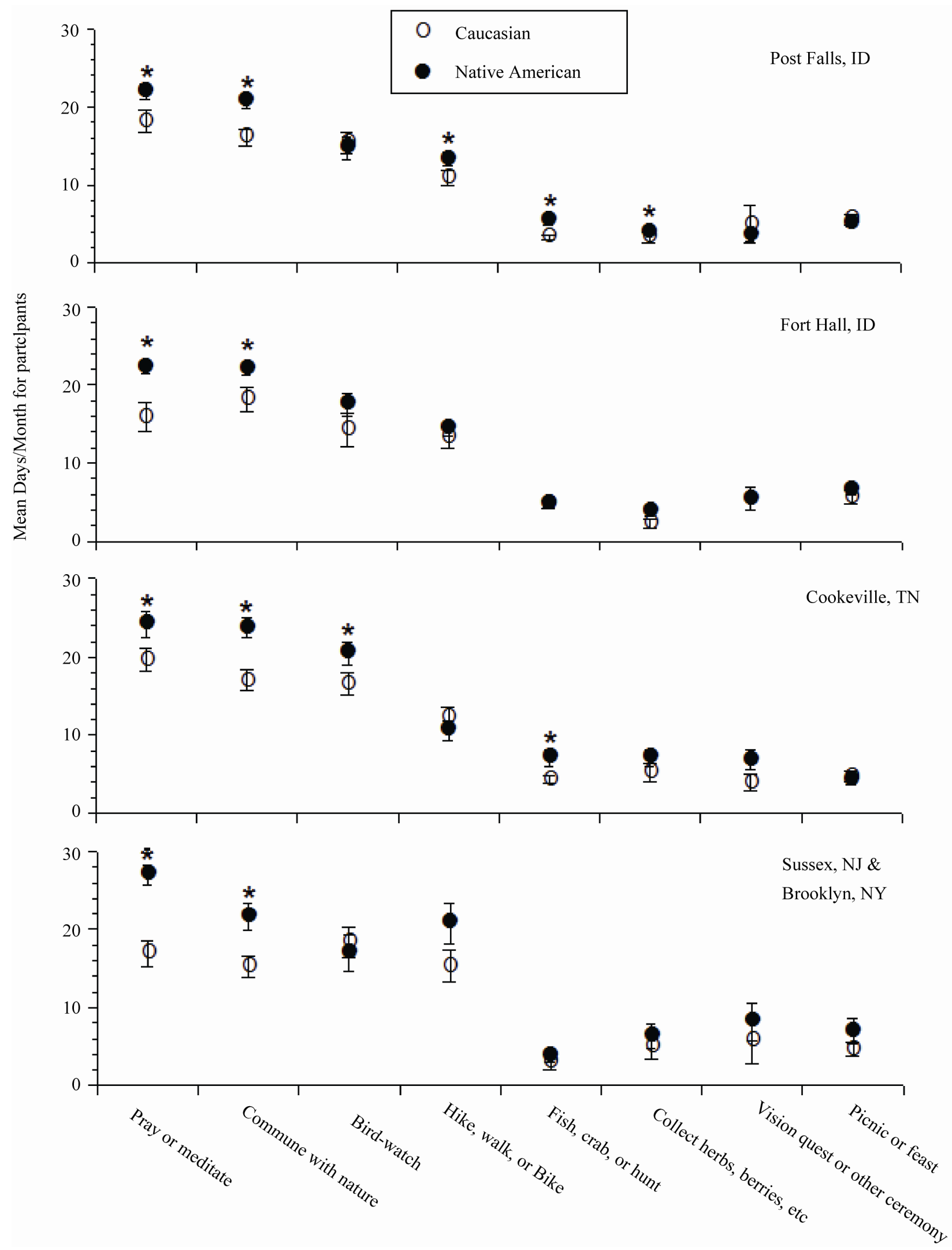

Figure 3. Frequency of specific activities for Native American and Caucasians interviewed at all locations. 
if they did, how often they engaged in these activities. However, subjects were also asked to rank the importance of 8 activities, where they could integrate their own participation with their cultural values. That is, subjects provided a value judgement for the importance of these activities to them. For example, people who do not en- gage in hunting might well believe hunting is important. In general, pray or meditate was given as the most important activity for most people (regardless of ethni- city), except for Ft. Hall, where fishing/hunting was more important for Caucasians (Figure 4). Commune with nature was the second most important activity for both Cooke-
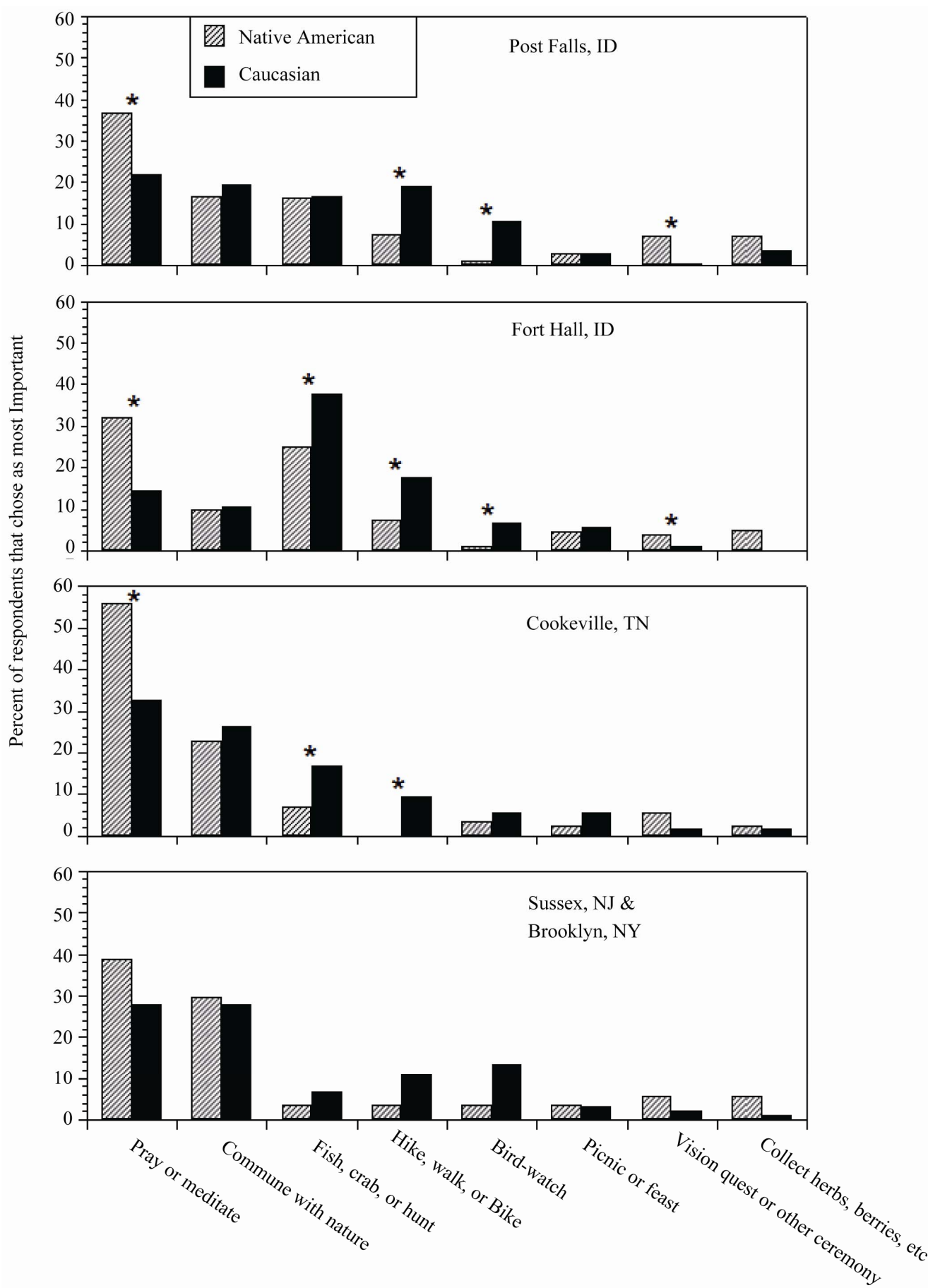

Figure 4. Percentage of most important activity for Native Americans and Caucasians interviewed all locations. Star indicated significant difference. 
ville and New Jersey/New York, and was tied for second at Post Falls.

\section{Discussion}

\subsection{Overall Participation and Activity Rates}

There is an extensive literature about hunting and fishing and other consumptive activities [19], and on recreational activities and leisure activities [20]. Activities of Native Americans, which often involve a full range of both consumptive and non-consumptive activities, have been well documented for some American Indians and Alaska Natives [21,22]. These papers, however, neither compare Native Americans with others, nor include consumptive, non-consumptive, and religious/cultural separately (but see Harper et al. [22] for only Native Americans).

The difficulty partly is one of terminology because there are several different ways of talking about activities performed in nature. In this paper, activities that clearly were consumptive (e.g. hunting, fishing, gathering), nonconsumptive (picnics, walking, biking, bird-watching), and religious/cultural (communicate with nature, pray or meditate, vision quest or other ceremony) were examined. Subjects could participate in any or all of the activities, and if they participated, could give estimates of their rates for each activity.

Overall, the greatest participation was for religious/ sacred activities, followed by fishing, camping and hiking, and then picnics. Participation rates, and activity rates, provide information that can be used by resource managers and land use managers to predict the types of resources to enhance or manage to meet the needs of the public. This type of information also provides insights into possible conflicts among users. The relative lower rate of hunting in Cookeville suggests less conflict with other, non-consumptive uses. Further, the relatively high rate of participation in fishing indicates that these resources are vital to local communities, and may require active management.

The activities the survey examined dealt with specific activities (e.g. hunt, fish, hike, camp), and not what they did or thought while engaging in these activities. However, when asked to rank (from 1 to 8) different activities, categories were combined (into hunt/fish/crab), and commune with nature was added. Commune with nature, along with engaging in religious/sacred activities were given as the activities that were "most important" to subjects. This illustrates that communing with nature is a key and important aspect of activities performed in wild environments, and suggests that this needs to be considered as an "activity" by scientists, in addition to more traditional hunting, fishing, camping and hiking.
Commune with nature, as well as hiking/walking, are activities that can be performed in small and nearby natural environments, while hunting, fishing and sacred activities may require larger natural environments that may be farther away. Subjects noted in conversa- tions that they often went to small parks, woodlots or other natural areas close to home to commune with nature or walk, while they often had to travel long distances to reach sacred grounds, or engage in camping.

\subsection{Location Differences}

Participation and activity rates varied among sites. Fishing participation rates were lower in New Jersey/New York, hunting was lower in New Jersey/New York and in Tennessee, gathering was higher in Post Falls, and camping and hiking were higher in the northwestern United States than for the other sites. Partly these differences may relate to availability of suitable habitat (e.g. there are fewer hunting opportunities nearby in New Jersey/New York than in the northwestern United States). However, they are likely due to cultural differences since there are places to hunt in all regions.

The remarkable similarity in the percentage of people engaging in each specific activity across the four sites indicates a general preference for these activities. This provides some uniformity in management directives that suggest that hiking, camping, and fishing are the high use activities. The further emphasis on religious/sacred activities supports the importance of relatively undisturbed environments.

\subsection{Native American versus Caucasian}

While several authors have described the holistic view of Native Americans about the natural environment $[4,8,23]$, few have examined the participation and activity rates of Native Americans and Caucasians living in the same region. While ethnic differences were present for some activities at some sites (particularly Post Falls and Ft. Hall), there were no significant ethnic differences for many consumptive and non-consumptive uses. Further, when overall consumptive and non-consumptive were considered (that is, did each subject engage in any consumptive or non-consumptive activity), there were no ethnic differences in non-consumptive, and no ethnic difference for subjects at Ft. Hall.

The ethnic differences in consumptive activities were greatest for Post Falls and New Jersey/New York. In both sites, Native Americans engaged in higher rates of consumptive activities than others, suggesting a particular need to track these differences, and manage resources accordingly. Ethnic differences in non-consumptive specific activities were less clear. It may be that Native Americans engage in camping, for example, as part of 
hunting and fishing trips, while others engage in camping as part of bird-watching or hiking. Thus, the overall activity (camping) did not generally vary by ethnicity (except for Post Falls), but the reason for doing so did.

\subsection{Exposure and Management}

The data presented in this paper can be used to understand potential exposure, both in terms of the percent of the population that may be exposed, and to the levels of exposure (days engaged in each activity). These data are useful for a range of risk assessors, risk managers, resource managers, land use managers, and public policy makers in understanding what percentage of people might engage in different types of activities, and the frequency of this engagement.

Use data are often presented as a function of the total population, where exposure in terms of days/month includes the entire population. In terms of risk and exposure, and even for land use, it is important to know how often people use resources who do indeed use them. Thus, if less than $10 \%$ of the population gather herbs and berries, but that $10 \%$ does so 5 tor 7 days a month (as they do at Tennessee), then to average exposure over the entire population reduces the known exposure, and perhaps management to reduce exposure. This is especially true for situations in which natural resources (such as fish, berries, or game) might be contaminated and one objective is to understand the population that is maximally exposed. And it is even more important to understand maximum exposure for high risk populations, such as pregnant women exposed to mercury (e.g. for fish consumption).

While having data on exposure is critical for risk assessors, risk managers, and health professionals, such data are also useful for land managers who have limited resources to manage opportunities for recreational and subsistence activities on natural lands. Further, the similarities and differences among sites provide information for federal and regional managers to allocate resources.

\section{Acknowledgements}

I thank M. Gochfeld, C. W. Powers, J. Clarke, M. Greenberg for helpful information and discussions about the complexities of environmental evaluation in relation to resource use and future land use, and C. Jeitner, T. Pittfield, R. Ramos, C. Dixon, and M. Marchioni for help with the interviews. We particularly thank Stephanie Jordan of the (tribe, committee) for permission to conduct these interviews at the Post Falls Julyamsh Pow Wow, Delbert Farmer and Tina Batt (tribal committee) for permission to conduct these interviews at the Shoshone-Bannock Pow Wow, Mary Cox and Carol Cash for permission to conduct these interviews at the "Pow
Wow on the Mountain" festival, and Cliff Matias for the Red Hawk Native American's Art Council (for New Jersey/ New York). This research was funded by the Consortium for Risk Evaluation with Stakeholder Participation (CRESP) through the Department of Energy (AI \# DE-FG 26-00NT 40938 and DE-FC01-06EW07053), NIEHS (P30ES005022), and EOHSI. The conclusions and interpretations reported herein are the sole responsibility of the author, and should not in any way be interpreted as representing the views of the funding agencies.

\section{REFERENCES}

[1] J. Cairns, "Rehabilitating Damaged Ecosystems," CRC Press, Boca Raton, 1994.

[2] J. Cairns and B. R. Niederlehner, "Developing a Field of Landscape Ecotoxicology," Ecological Applications, Vol. 6, No. 3, 1995, pp. 780-796.

[3] M. Greenberg, J. Burger, M. Gochfeld, D. Kosson, K. Lowrie, H. Mayer, et al., "End-State Land Uses, Sustainably Protective Systems, and Risk Management: A Challenge for Remediation and Multigenerational Stewardship," Remediation, Vol. 16, No. 1, 2005, pp. 91-105. doi:10.1002/rem.20072

[4] J. Burger, M. Gochfeld, K. Pletnikoff, R. Snigaroff, D. Snigaroff and T. Stamm, "Ecocultural Attributes: Evaluating Ecological Degradation: Ecological Goods and Services vs Subsistence and Tribal Values," Risk Analysis, Vol. 28, No. 5, 2008, pp. 1261-1271. doi:10.1111/j.1539-6924.2008.01093.x

[5] R. W. Stoffle and J. J. Evans, "Holistic Conservation and Cultural Triage: American Indian Perspectives on Cultural Resources," Human Organization, Vol. 49, No. 2, 1990, pp. 91-99.

[6] M. L. Tano, J. H. Reuben, D. Powaukee and A. D. Lester, "An Indian Tribal View of the Back End of the Nuclear Fuel Cycle: Historical and Cultural Lessons," Radwaste, Vol. 3, No. 2, 1996, pp. 44-47.

[7] S. G. Harris and B. L. Harper, "Native American Exposure Scenario," Risk Analysis, Vol. 17, No. 6, 1997, pp. 789-795. doi:10.1111/j.1539-6924.1997.tb01284.x

[8] S. G. Harris and B. L. Harper, "How Incorporating Tribal Information Will Enhance Waste Management Decisions," Confederated Tribes of the Umatilla Indian Reservation, Pendleton, 2008.

[9] Nez Perce Tribe, "Treaties: Nez Perce Perspectives," US DOE and Confluence Press, Fallon, 2003.

[10] L. M. Stumpff, "Reweaving the Earth: An Indigenous Perspective on Restoration Planning and the National Environmental Policy Act," Environmental Practice, Vol. 8, No. 2, 2006, pp. 93-103. doi:10.1017/S1466046606060121

[11] G. Bohnee, J. Mathews, J. Pinkham, A. Smith and J. Stanfill, "Nez Perce Involvement with Solving Environmental Problems: History, Perspectives, Treaty Rights, and Obligations," In: J. Burger, Ed., Science and Stake- 
holders: Solutions to Energy and Environmental Issues by Incorporating Resource Agencies, Regulators, Tribes, Industry, and Other Stakeholders, Springer, New York, 2011.

[12] Y. Yin and J. T. Pierce, "Integrated Resource Assessment and Sustainable Land Use," Environmental Management, Vol. 17, No. 3, 1993, pp. 319-327. doi:10.1007/BF02394674

[13] G. W. Suter, R. A. Efroymson, B. E. Sample and S. D. Jones, "Ecological Risk Assessment for Contaminated Sites," Lewis Publishers, Boca Raton, 2000. doi:10.1201/9781420056693

[14] K. D. Crowley and J. F. Ahearne, "Managing the Environmental Legacy of U.S. Nuclear-Weapons Production," American Scientist, Vol. 90, No. 6, 2002, pp. 514-523.

[15] R. A. Efroymson, J. P. Nicolette and G. W. Suter, "A Framework for Net Environmental Benefit Analysis for Remediation or Restoration of Petroleum-Contaminated Sites," ORNL/TM-2003/17, Oak Ridge National Laboratory, Oak Ridge, 2003.

[16] V. H. Dale and P. D. Parr, "Preserving DOE's Research Parks," Issues in Science and Technology, Vol. 14, No. 2, 1998, pp. 73-77.

[17] Department of Energy (DOe), "Environmental Justice: Five-Year Implementation Plan," DOE/LM-1462, Office of Legacy Management, Grand Junction, Colorado, 2008.
[18] SAS Institute, "User's Guide to SAS," SAS Publishing, Cary, 1995.

[19] S. J. Backman and B. A. Wright, "An Exploratory Study of the Relationship of Attitude and the Perception of Constraints to Hunting," Journal of Park and Recreation Administration, Vol. 11, No. 2, 1993, pp. 1-16.

[20] D. Scott and C. S. Shafer, "Recreational Specialization: A Critical Look at the Construct," Journal of Leisure Research, Vol. 33, No. 3, 2001, pp. 319-343.

[21] R. G. Condon, P. Collings and G. Wenzel, "The Best Part of Life: Subsistence Hunting, Ethnicity, and Economic Adaptation among Young Adult Inuit Males," Arctic, Vol. 48, No. 1, 1995, pp. 31-46.

[22] B. L. Harper, A. D. Harding, T. Waterhous and S. G. Harris, "Traditional Tribal Subsistence Exposure Scenario and Risk Assessment Guidance Manual," US Environmental Protection Agency EPA-STAR-J1-R831-46, 2008.

http://www.hhs.oregonstate.edu/ph/sites/default/files/xpo sure_Scenario_and_Risk_Guidance_Manual_v2.pdf

[23] S. G. Harris and B. L. Harper, "Using Eco-Cultural Dependency Webs in Risk Assessment and Characterization of Risks to Tribal Health and Cultures," Environmental Science and Pollution Research, Vol. 2, 2000, pp. 91-100. 